\title{
ANALISIS FAKTOR PENYEBAB UTAMA KECENDERUNGAN BUNUH DIRI DI KALANGAN REMAJA YANG BERUSIA 15-17 TAHUN DI MAKASSAR
}

\author{
Hermin Mallo \\ Daniel Ronda.
}

\begin{abstract}
ABSTRAK
Pokok masalah penelitian ini ialah apa yang menjadi penyebab utama terjadinya kasus bunuh diri di kalangan remaja yang berusia 15 sampai 17 tahun? Adapun tujuan penulisan ini adalah sebagi berikut: memberitahukan kepada pembaca bahwa yang menjadi penyebab utama terjadinya kasus bunuh diri adalah masalah yang dihadapi oleh remaja yang berusai 15-17 tahun dengan keluarga mereka. Penyebab lainnya adalah depresi dan konsep diri yang keliru. Dalam penelitian ini yang menjadi populasi adalah siswa berusia 15 sampai 16 tahun (kelas $\mathcal{X}$ ) di SMU Kristen Diakui Makassar, dan siswa berusia 15-17 tahun (kelas $\mathcal{X}$ dan XI) di SMA Gamaliel Makassar. Sampel dalam penelitian ini adalah siswa kelas $\chi$ di SMU Kristen Diakui Makassar, dan siswa kelas XI PIA 2 dan kelas XI PIS, kelas $\mathcal{X}-5$ di SMU Gamaliel Makassar. Dalam penelitian ini, penulis menggunakan teknik pengumpulan data melalui wawancara, angket, dan observasi. Teknik analisis data ialah analisis statitik dengan program SPSS 15. Hasil penelitian ini ialah ada tiga masalah yang dihadapi oleh remaja yang berniat melakukan bunuh diri, yaitu: Depresi. Depresi yang mereka alami adalah puncak dari semua perasaan bersalah, marah, tidak berarti dan tidak diinginkan. Depresi yang berat menjadi salah satu penyebab terjadinya bunuh diri. Konsep diri. Masalah konsep diri banyak dialami oleh remaja. Konsep diri yang keliru membuat mereka merasa tidak diinginkan, tidak berharga dan tidak seorang pun mengasihi mereka. Konsep diri yang salah ini juga dipengaruhi oleh teman sebaya mereka. Remaja berusaha untuk menjadi eperti yang diinginkan oleh teman sebaya agar mereka bias diterima dan diakui oleh kelompok teman sebaya mereka. Hubungan dalam keluarga. Hubungan dalam keluarga menyangkut perceraian orang tua mereka dan penerimaan dari orang tua. Perceraian orang tua melukai anak remaja dan membuat mereka merasa tidak dikasihi dan menyalahkan diri atas perceraian itu. Orang tua yang tidak menerima anak remajanya sebagai diri mereka sendiri memuat remaja berusaha untuk menjadi orang lain dan merasa orang tua mereka baru akan mengasihi mereka saat mereka menjadi remaja yang orang tua mereka inginkan bukannya menjadi mereka sendiri.
\end{abstract}

\section{PENDAHULUAN}

\section{Latar Belakang Masalah}

Remaja yang mengalami masalah banyak yang mencari jawabannya sendiri dengan cara yang salah. Salah satunya dengan mengakhiri hidup mereka sendiri dengan bunuh diri. Stephen Arterburn memberikan beberapa fakta mengenai bunuh diri:

Bunuh diri remaja, penyebab kematian utama nomor tiga di kalangan mereka, telah menjadi tiga kali lipat dalam tiga puluh tahun terakhir. Sebagian besar remaja berpikir tentang bunuh diri. Sebesar 73 persen, khususnya, pernah terpikir untuk melakukan tindakan bunuh diri. Sebanyak 27 persen ternyata pernah mencobanya. Lebih banyak wanita dibandingkan pria yang bunuh diri. Namun, lebih banyak pria yang menemui ajal karena bunuh diri. Remaja berkecenderungan bunuh diri setidaknya pernah mengalami: kehilangan salah satu orang tua sebelum usia 12 tahun, pelecehan secara fisik maupun seksual, atmosfir 
keluarga yang diwarnai dengan ucapan "perceraian" atau "perpisahan" keluarga dengan riwayat depresi, dan penyakit kronis yang dihadapi ayah dan ibu.

Dari pengalaman, penulis melihat bahwa remaja yang berusia 15-17 tahun terdapat kecenderungan untuk melakukan percobaan bunuh diri. Kecenderungan ini tampak di kotakota besar. Jika kecenderungan ini tidak segera diatasi maka hal ini akan tumbuh menjadi sebuah tren dan fenomena di kalangan remaja di kota-kota besar, termasuk Makassar.

Kasus bunuh diri pada remaja terus mengalami peningkatan. Alasan mereka untuk melakukan hal ini beragam, akan tetapi pada dasarnya mereka melakukannya karena mereka berpikir tidak ada jalan keluar untuk masalahnya dan kematian adalah jalan keluar satusatunya. Kasus bunuh diri pada remaja pernah penulis jumpai sendiri sewaktu penulis duduk di bangku SMA.

Di Makassar sendiri menurut data dari kepolisian yang penulis peroleh melalui wawancara langsung dengan seorang bagian data Reskrim:

Pada tahun 2003 terdapat 31 kasus penemuan mayat dan bunuh diri yang dilaporkan dan hanya 13 kasus yang berhasil diselesaikan. Pada tahun 2004 ada 20 kasus yang dilaporkan dan 7 dari kasus tersebut berhasil diselesaikan. Tahun 2005 ada 30 kasus dan 7 dari kasus tersebut berhasil diselesaikan. Tahun 2006 ada 26 kasus yang dilaporkan dan hanya 6 kasus yang berhasil diselesaikan. ${ }^{2}$

Selain data yang diperoleh penulis dari kantor kepolisian Makassar penulis juga mendapatkan data dari rumah sakit Bhayangkara di Makassar mengenai angka bunuh diri. Menurut data dari Rumah Sakit Bhayangkara yang penulis peroleh melalui wawancara langsung dengan salah seorang dari bagian Rekamedis, "Pada bulan Februari 2009, ada 4 kasus percobaan bunuh diri, salah satunya adalah seorang gadis berusia 15 tahun bernama Salma, melakukan percobaan bunuh diri dengan cara meminum bensin sebanyak setengah liter, diduga anak tersebut melakukan percobaan bunuh diri karena depresi." ${ }^{3}$ Data yang didapatkan oleh penulis ini membuktikan bahwa betapa kasus bunuh diri dikalangan remaja ini harus mendapatkan perhatian khusus dari semua pihak, terutama orang tua dari remaja itu sendiri.

Orang tua dan lingkungan yang berada di sekitar mereka semestinya mengambil peran penting dalam kasus bunuh diri. Seorang remaja yang masih labil merasakan tidak ada orang yang mengasihi mereka, bahkan keluarga mereka juga cenderung bersikap menolak mereka, kemungkinan akan merasa depresi dan putus asa. "Jika seseorang terlalu lama terhanyut oleh rasa putus asa, pada akhirnya hal itu akan menimbulkan perasaan ingin mati dan bunuh diri saja.." ${ }^{4}$ Kurangnya perhatian bahkan tanggapan dari orang tua bahkan lingkungan terhadap keadaan ini membuat banyak remaja akhirnya tidak dapat ditolong dan harus mengakhiri hidupnya. Sikap acuh orang tua dan kurangnya pembinaan serta perhatian khusus kepada anak remaja yang mengalami masalah seperti ini membuat penulis tertarik untuk membahasnya dalam sebuah karya ilmiah

\section{Pokok Masalah}

Dengan mengamati latar belakang masalah di atas, maka penulis memusatkan perhatian pada pokok masalah, yakni: apa yang menjadi penyebab utama terjadinya kasus bunuh diri di kalangan remaja yang berusia 15 sampai 17 tahun?

\footnotetext{
${ }^{1}$ Stephen Arterburn dan Jim Burns, Arahkan Dengan Jitu (Yogyakarta: ANDI, 2006), 124.

${ }^{2}$ Aswin, Wawancara Oleh Penulis, Makassar, Sulawesi Selatan, 14 April 2009.

${ }^{3}$ Nova, Wawancara Oleh Penulis, Makassar, Sulawesi Selatan, 1 April 2009

${ }^{4}$ Derrek Prince, Rasa Tertolak Bagaimana Mengatasinya (Jakarta: Yayasan Pekabaran Injil Imanuel, 1994),
} 


\section{Tujuan Penulisan}

Adapun tujuan penulisan ini adalah sebagi berikut: memberitahukan kepada pembaca bahwa yang menjadi penyebab utama terjadinya kasus bunuh diri adalah masalah yang dihadapi oleh remaja yang berusai 15-17 tahun dengan keluarga mereka. Penyebab lainnya adalah depresi dan konsep diri yang keliru.

\section{Manfaat Penulisan}

Beberapa manfaat yang diharapkan dapat dicapai dalam penulisan karya ilmiah ini adalah: Pertama, supaya setiap orang yang membaca tulisan ini mengetahui bahwa anak remaja juga memiliki potensi yang besar untuk melakukan bunuh diri dan mengetahui cara untuk menolong mereka. Kedua, supaya setiap orang tua lebih menyadari masalah yang dihadapi anak remaja saat ini. Ketiga, sebagai suatu acuan bagi pembina rohani dan pembina remaja secara khusus agar memberikan perhatian kepada remaja yang bermasalah terutama pada usia 15 sampai 17 tahun.

\section{Definisi-Definisi}

Kata "bunuh diri" berarti, "Tindakan menghilangkan nyawa sendiri dengan menggunakan segala cara." Sedangkan kata "remaja" berarti, "Masa peralihan antara masa anak dan masa dewasa yakni antara 12 sampai 21 tahun." Menurut Kamus Besar Bahasa Indonesia, kata "psikologi” artinya, "Ilmu yang berkaitan dengan proses-proses mental yang berpengaruh pada perilaku."

\section{METODOLOGI PENELITIAN}

Dalam penelitian ini penulis mengambil lokasi penelitian di dua tempat, untuk mewakilkan usia 15-17 tahun penulis mengambil sampel dari SMU Kristen Diakui Makassar dan SMA Gamaliel.

\section{Jenis Penelitian}

Jenis data yang digunakan oleh penulis adalah data kuantitatif. "Data ini dinyatakan dalam bentuk jumlah atau angka yang dapat dihitung secara matematik dan di dalam penelitian dilakukan dengan mempergunakan rumus-rumus statistika." 8 Penulis menyebarkan angket yang menjadi sumber data selain data dari rumah sakit dan kepolisian. Angket diberikan kepada siswa kelas X di SMU Kristen Diakui Makassar dan kelas X-5, XI PIA 2 dan XI PIS di SMA Gamaliel Makassar.

\section{Populasi}

Dalam penelitian penelitian ini yang menjadi populasi adalah siswa berusia 15 sampai 16 tahun (kelas X) di SMU Kristen Diakui Makassar, dan siswa berusia 15-17 tahun (kelas X dan XI) di SMA Gamaliel Makassar.

\footnotetext{
${ }^{5}$ Wilkipedia Indonesia: Ensiklopedia Bebas Berbahasa Indonesia, s.v. "bunuh diri." Diakses 23 Maret 2009; tersedia di http://id.wikipedia.org/wiki/Bunuh diri "kategori: rintisan bertopik kematian."

${ }^{6}$ Singgih D. Gunarsa dan Y. Singgih D. Gunarsa, Psikologi Perkembangan Anak dan Remaja (Jakarta: Gunung Mulia, 1983), 203.

"Kamus Besar Bahasa Indonesia, s.v. "psikologi."

${ }^{8}$ Hadari Nawawi dan Martini Hadari, Instrumen Penelitian Bidang Sosial (Yogyakarta: Gajah Mada University Press, 1992), 53.
} 


\section{Sampel}

Sampel dalam penelitian ini adalah siswa kelas X di SMU Kristen Diakui Makassar, dan siswa kelas XI PIA 2 dan kelas XI PIS, kelas X-5 di SMU Gamaliel Makassar.

\section{Teknik Pengumpulan Data}

Dalam penelitian penelitian ini, penulis menggunakan teknik pengumpulan data melalui wawancara, angket, dan observasi. Pertama, wawancara adalah "tanya jawab lisan antara dua orang atau lebih secara langsung." Selain itu wawancara juga adalah "proses memperoleh keterangan untuk tujuan penelitian dengan cara tanya jawab sambil bertatap muka antara si penanya atau pewawancara dengan si penjawab atau responden dengan menggunakan alat yang dinamakan interview guide (panduan wawancara)."10 Dari wawancara ini penulis memperoleh data tentang kasus bunuh diri remaja dari Rumah Sakit, Kantor Polisi dan siswa dari Sekolah Kristen. Kedua, angket, yaitu "Daftar pernyataan atau pertanyaan yang dikirimkan kepada responden baik secara langsung atau tidak langsung (melalui pos atau perantara)." ${ }^{11}$ Angket yang diberikan kepada siswa di kedua sekolah ini berisi 36 pertanyaan. Angket yang digunakan dalam penelitian ini bersifat tertutup sehingga responden dapat memberikan jawaban sesuai dengan keadaan yang dialami dengan mengisi alternatif jawaban yang telah disediakan. Ketiga, observasi adalah "Pengamatan dan pencatatan yang sistematis terhadap gejala-gejala yang diteliti." ${ }^{2}$ Yang diobservasi pada penelitian ini adalah keadaan psikologi remaja Makassar yang mengalami perceraian orang tua mereka, kehilangan orang yang berarti bagi mereka (karena kematian), dan depresi yang mereka alami terhadap keinginan remaja untuk melakukan bunuh diri.

\section{Teknik Analisis Data}

Pengetahuan akan pengertian teknik pengumpulan data dapat menolong penulis untuk dapat mengetahui dengan jelas teknik apa yang akan peneliti gunakan dalam penelitian ini. Melalui data yang dipeoleh oleh penulis maka teknik analisis data yang digunakan adalah: statistik, yaitu "Keterangan-keterangan berupa angka-angka yang mempergunakan proses pengumpulan dan pengukuran, klasifikasi dan analisa, pembuat keputusan dan komunikasi hasil-hasil dengan cara yang dapat dipahami dan dapat diperiksa kebenarannya oleh pihak lain." ${ }^{33}$ Dalam pengertian yang lebih luas, "Statistik berarti cara-cara ilmiah yang dipersiapkan untuk mengumpulkan, menyusun, menyajikan dan menganalisa data penyelidikan yang berwujud angka-angka." ${ }^{4}$

Regresi. "Istilah regresi juga digunakan dalam analisis statistic yang digunakan dalam mengembangkan suatu persamaan yang meramalkan sesuatu variable dari variable kedua yangtelah diketahui." ${ }^{15}$ Dalam penelitian ini penulis menggunakan analisis regresi berganda. "Analisis regresi ganda digunakan oleh peneliti, bila peneliti bermaksud meramalkan bagaimana

\footnotetext{
${ }^{9}$ Husaini Usman dan Purnomo Setiady Akbar, Metodologi Penelitian Sosial (Jakarta: Bumi Aksara, 1996), 43.

${ }^{10}$ Moh. Nazir, Metode Penelitian (Jakarta: Ghalia Indonesia, 1988), 234.

${ }^{11}$ Husaini Usman dan Purnomo Setiady Akbar, Metodologi Penelitian Sosial (Jakarta: Bumi Aksara, 1996),

43.

${ }^{12}$ Ibid.

${ }^{13}$ Komarudin, Kamus Riset (Bandung: Angkasa, 1984), 263.

${ }^{14}$ Sutrisno Hadi, Metodologi Research 3 (Yogyakarta: Yayasan Penerbit Fakultas Psilologi Universitas Gadjah Mada, 1987), 221.

${ }^{15}$ Suharsimi arikunto. Prosedur Penelitian Suatu Pendekatan Praktis (Jakarta: PT. Melton Putra, 1991), 235
} 
keadaan (naik turunnya) vaiabel dependen (kriterium), bila dua atau lebih variable independen sebagai predictor dimanipulasi (dinaik turunkan nilainya)." ${ }^{.16}$ Rumus yang digunakan dalam penelitian ini adalah:

$$
\mathrm{Y}=\mathrm{a}+\mathrm{b} 1 \mathrm{Xl}+\mathrm{b} 2 \mathrm{X} 2+\mathrm{B} 3 \mathrm{X} 3
$$

\section{ANALISIS HASIL DAN PEMBAHASAN}

\section{Analisis Data Bunuh Diri}

Tabel 10: Mean dan Median Data Bunuh Diri

\begin{tabular}{|ll|r|}
\hline N & Valid & 86 \\
& Missing & 0 \\
Mean & & 40.88 \\
Std. Error of Mean & .394 \\
Median & & 42.00 \\
Std. Deviation & & 3.654 \\
Variance & & 13.351 \\
Percentiles & 25 & 39.00 \\
& 50 & 42.00 \\
& 75 & 44.00 \\
\hline
\end{tabular}

Tabel ini menunjukkan kepada kita nilai rata-rata (mean) dari pertanyaan mengenai bunuh diri adalah 40,88 dan nilai tengah (median) yang diperoleh adalah 4 .

Tabel 1l: Frekuensi Data Bunuh Diri

\begin{tabular}{|r|r|r|r|r|}
\hline & $\begin{array}{r}\text { Frequenc } \\
\text { y }\end{array}$ & Percent & \multicolumn{1}{|c|}{$\begin{array}{c}\text { Valid } \\
\text { Percent }\end{array}$} & $\begin{array}{c}\text { Cumulative } \\
\text { Percent }\end{array}$ \\
\hline Valid 29 & 1 & 1.2 & 1.2 & 1.2 \\
32 & 3 & 3.5 & 3.5 & 4.7 \\
33 & 2 & 2.3 & 2.3 & 7.0 \\
35 & 2 & 2.3 & 2.3 & 9.3 \\
36 & 4 & 4.7 & 4.7 & 14.0 \\
37 & 4 & 4.7 & 4.7 & 18.6 \\
38 & 4 & 4.7 & 4.7 & 23.3 \\
39 & 3 & 3.5 & 3.5 & 26.7 \\
40 & 3 & 3.5 & 3.5 & 30.2 \\
41 & 14 & 16.3 & 16.3 & 46.5 \\
42 & 11 & 12.8 & 12.8 & 59.3 \\
43 & 11 & 12.8 & 12.8 & 72.1 \\
44 & 15 & 17.4 & 17.4 & 89.5 \\
45 & 9 & 10.5 & 10.5 & 100.0 \\
Total & 86 & 100.0 & 100.0 & \\
\hline
\end{tabular}

\footnotetext{
${ }^{16}$ Sugiyono. Statistika untuk Penelitian (Bandung: Alfabeta,2005),250
} 
Tabel di atas menunjukkan bahwa, 16 orang responden atau 18,6\%, memiliki nilai di bawah 37 dan mereka ini cenderung untuk melakukan percobaan bunuh diri. Mereka pernah memberitahukan kepada orang lain keinginan mereka untuk bunuh diri, merasa ingin mati, sering menempuh resiko yang berbahaya akhir-akhir ini, bahkan ada yang telah melakukan percobaan bunuh diri. Tabel juga menunjukkan 35 orang atau $40,7 \%$ responden memiliki nilai 38-42. Mereka ini adalah responden yang memiliki potensi untuk melakukan percobaan bunuh diri. Mereka mulai memikirkan tentang akan mati bahkan mulai melakukan hal-hal yang beresiko, akan tetapi mereka belum menyatakan kepada seseorang keinginan untuk bunuh diri. Tetapi tidak tertutup kemungkinan mereka ini akan berubah dari responden yang memiliki potensi untuk bunuh diri menjadi responden yang memiliki kecenderungan untuk melakukannya jika mereka tidak segera ditolong. Tabel di atas juga menunjukkan bahwa ada 35 responden atau 40,7\% responden memiliki nilai 43-45, mereka ini adalah orang yang tidak pernah memiliki pemikiran untuk bunuh diri ataupun melakukan hal-hal yang beresiko tinggi.

\section{Bunuh Diri}

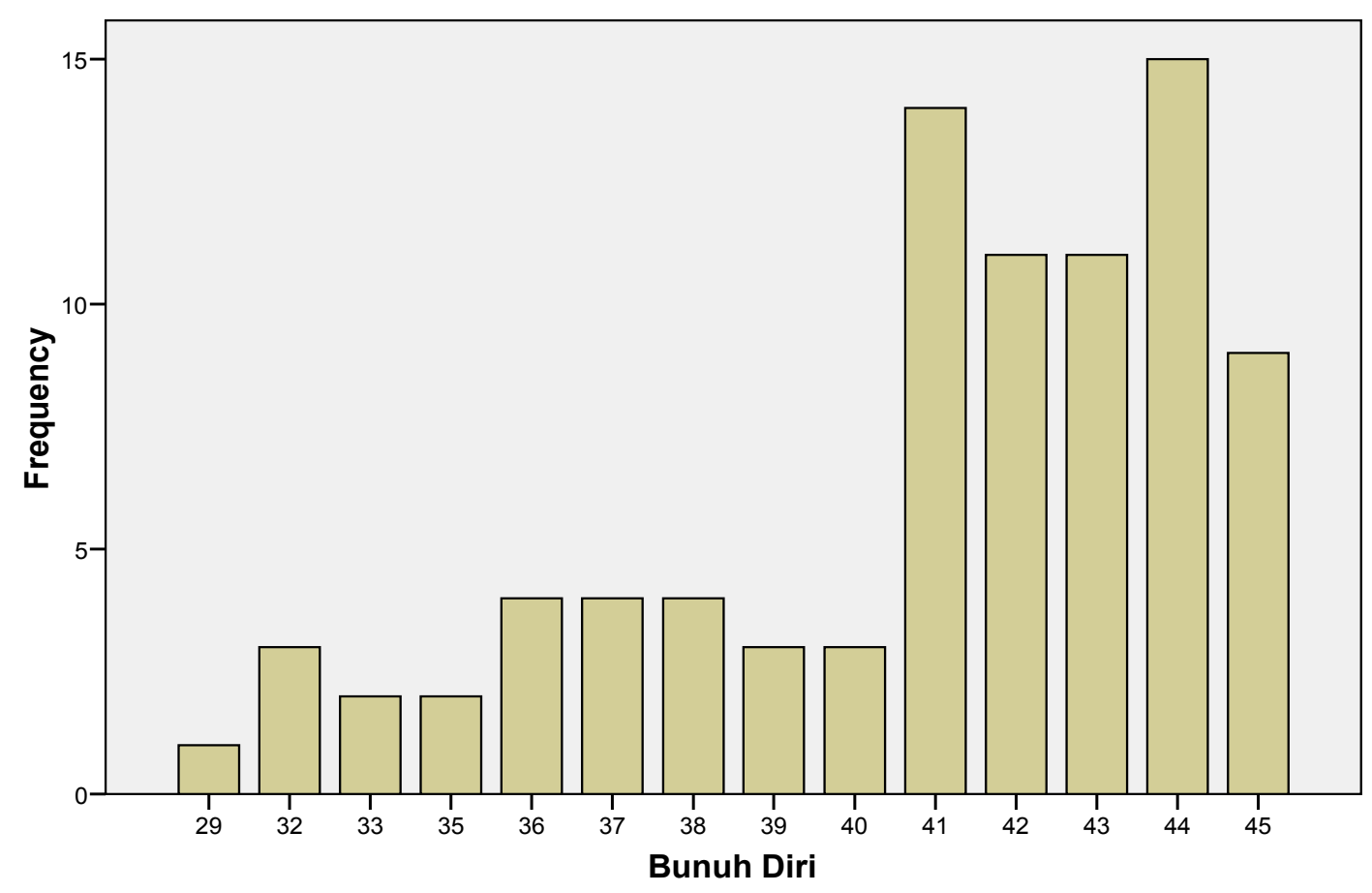

Diagram di atas menunjukkan bahwa mereka yang memiliki nilai di bawah 37 atau mereka yang termasuk memiliki kecenderungan untuk melakukan bunuh diri memiliki frekuensi yang sedikit yaitu 4 sedangkan responden yang memiliki nilai 38-42 yaitu mereka yang memiliki potensi untuk melakukan percobaan bunuh diri memiliki frekuensi yang tinggi yaitu 14. Untuk responden yang memiliki nilai 43-45 yaitu responden yang tidak memiliki keinginan untuk bunuh diri memiliki frekuensi yang paling tinggi yaitu 15. Tetapi hal yang perlu diingat adalah frekuensi antara responden yang berpotensi untuk melakukan percobaan bunuh diri dengan yang tidak pernah memilikirkan tentang bunuh diri sangatlah tipis perbedaannya. 


\section{Hubungan Rata-Rata Faktor Keluarga, Kesehatan, Emosi dan Bunuh Diri dengan Jenis Kelamin Responden}

\begin{tabular}{lccrc}
$\begin{array}{l}\text { Jenis } \\
\text { Kelamin }\end{array}$ & $\begin{array}{c}\text { Keluarga } \\
\text { Mean }\end{array}$ & $\begin{array}{c}\text { Kesehatan } \\
\text { Mean }\end{array}$ & $\begin{array}{c}\text { Emosi } \\
\text { Mean }\end{array}$ & $\begin{array}{c}\text { Bunuh Diri } \\
\text { Mean }\end{array}$ \\
\cline { 1 - 2 } & 18 & 9 & 59 & 40 \\
Laki-laki & 18 & 9 & 55 & 41
\end{tabular}

Tabel menunjukkan bahwa, baik laki-laki maupun perempuan memiliki nilai rata-rata 18 untuk keluarga yang berarti mereka berasal dari keluarga yang sedang-sedang. Untuk kondisi kesehatan juga tidak jauh beda, baik perempuan maupun laki-laki memiliki kondisi kesehatan yang tidak terlalu buruk, tetapi tidak juga membuat mereka berputus asa dan meminum obat tidur tanpa petunjuk dari dokter. Untuk kondisi emosi terlihat bahwa laki-laki memiliki emosi yang lebih baik (menuju ke arah yang lebih baik) daripada perempuan. Kebanyakan perempuan sering merasa tertekan, sedih, ingin menangis dan juga cepat cemas. Untuk bunuh diri sikap mereka tidak jauh beda mereka berpotensi untuk melakukan bunuh diri.

\section{Hubungan Rata-Rata Keluarga, Kesehatan, Emosi dan Bunuh Diri dengan Kelas Responden}

\begin{tabular}{|c|c|c|c|c|}
\hline Kelas & $\begin{array}{l}\text { Keluarga } \\
\text { Mean }\end{array}$ & $\begin{array}{l}\text { Kesehatan } \\
\text { Mean }\end{array}$ & $\begin{array}{l}\text { Emosi } \\
\text { Mean }\end{array}$ & $\begin{array}{l}\text { Bunuh Dir } \\
\text { Mean }\end{array}$ \\
\hline X & 18 & 9 & & 40 \\
\hline XI & 18 & 9 & & 42 \\
\hline
\end{tabular}

Untuk faktor keluarga baik kelas X maupun kelas XI keduanya memiliki kondisi keluarga yang sedang-sedang. Tidak terlalu menyenangkan tapi tidak sampai membuat mereka ingin pergi dari rumah. Untuk kondisi kesehatan juga sama. Kelas X dan XI sama-sama memiliki kesehatan yang sedang-sedang, tidak sampai membuat mereka meminum obat tanpa petunjuk dari dokter. Untuk kondisi emosi mereka kelas X dan XI berada dalam kondisi emosi yang sedang-sedang juga, akan tetapi kelas X lebih menunjukkan tingkat emosi yang lebih baik dari kelas XI. Untuk keinginan bunuh diri keduanya berpotensi untuk melakukan percobaan bunuh diri. Tetapi, kelas XI lebih mengarah kepada kondisi tidak memikirkan bunuh diri sedangkan kelas X lebih kepada kondisi cenderung melakukan percobaan bunuh diri.

Tabel 12: Coefisien a (Constant)

\begin{tabular}{|c|c|c|c|c|c|}
\hline \multirow[b]{2}{*}{$\begin{array}{l}\text { Mode } \\
1\end{array}$} & \multicolumn{2}{|c|}{$\begin{array}{l}\text { Unstandardized } \\
\text { Coefficients }\end{array}$} & \multirow{2}{*}{$\begin{array}{c}\begin{array}{c}\text { Standardize } \\
\mathrm{d}\end{array} \\
\text { Coefficients } \\
\text { Beta }\end{array}$} & \multirow{2}{*}{$t$} & \multirow{2}{*}{$\begin{array}{l}\text { Sig. } \\
\text { Std. } \\
\text { Error }\end{array}$} \\
\hline & B & $\begin{array}{l}\text { Std. } \\
\text { Error }\end{array}$ & & & \\
\hline$\overline{\text { (Cons }}$ & 24.395 & 3.793 & & 6.432 & .000 \\
\hline
\end{tabular}




\begin{tabular}{|l|r|r|r|r|r|}
\hline t) & & & & \\
Keluarga & .443 & .154 & .293 & 2.869 & .005 \\
Kesehata & .166 & .379 & .046 & .436 & .664 \\
$\mathrm{n}$ & .120 & .046 & .291 & 2.640 & .010 \\
Emosi &
\end{tabular}

Tabel di atas menunjukkan nilai a (constant) adalah 6,432, nilai X1 2,869, nilai X2 0, 436 dan nilai X3 adalah 2,640. Persamaan regresinya adalah $\mathrm{Y}=\mathrm{a}+\mathrm{blXl}+\mathrm{b} 2 \mathrm{X} 2+\mathrm{b} 3 \mathrm{X} 3$ di mana:

Y : adalah tidak melakukan bunuh diri

$\mathrm{Xl}$ : nilai keluarga

$\mathrm{X} 2$ : nilai kesehatan

$\mathrm{X} 3$ : nilai emosi

$\mathrm{Y}=6,432+2,869 \mathrm{X} 1+0,436 \mathrm{X} 2+2,640 \mathrm{X} 3$. Perkiraan nilai Y(tidak melakukan bunuh diri) adalah $\mathrm{Y}=12,377$

Hal ini berarti tanpa faktor keluarga, kesehatan dan emosi kondisi tidak melakukan bunuh diri tetap bernilai 6,432 (constant). Jika nilai keluarga, kesehatan dan emosi terus bertambah, maka nilai untuk tidak melakukan bunuh diri juga semakin besar. Tetapi sebaliknya jika nilai keluarga, kesehatan dan emosi terus berkurang, maka nilai untuk tidak bunuh diri semakin kecil dan nilai untuk bunuh diri semakin besar.

\section{KESIMPULAN}

Orang tua, gereja dan pembina rohani harus menyadari bahwa remaja saat ini memiliki beberapa masalah yang membuat mereka memiliki niat untuk melakukan percobaan bunuh diri. Pertama, pendapat yang dikemukakan oleh Stephen Alterburn mengenai bunuh diri telah menjadi suatu tren kecenderungan untuk melakukan bunuh diri di Makassar. Kedua, ada tiga masalah yang dihadapi oleh remaja yang berniat melakukan bunuh diri, yaitu: Depresi. Depresi yang mereka alami adalah puncak dari semua perasaan bersalah, marah, tidak berarti dan tidak diinginkan. Depresi yang berat menjadi salah satu penyebab terjadinya bunuh diri. Konsep diri. Masalah konsep diri banyak dialami oleh remaja. Konsep diri yang keliru membuat mereka merasa tidak diinginkan, tidak berharga dan tidak seorang pun mengasihi mereka. Konsep diri yang salah ini juga dipengaruhi oleh teman sebaya mereka. Remaja berusaha untuk menjadi eperti yang diinginkan oleh teman sebaya agar mereka bias diterima dan diakui oleh kelompok teman sebaya mereka. Hubungan dalam keluarga. Hubungan dalam keluarga menyangkut perceraian orang tua mereka dan penerimaan dari orang tua. Perceraian orang tua melukai anak remaja dan membuat mereka merasa tidak dikasihi dan menyalahkan diri atas perceraian itu. Orang tua yang tidak menerima anak remajanya sebagai diri mereka sendiri memuat remaja berusaha untuk menjadi orang lain dan merasa orang tua mereka baru akan mengasihi mereka saat mereka menjadi remaja yang orang tua mereka inginkan bukannya menjadi mereka sendiri.

\section{Saran-Saran}

Berdasarkan kesimpulan di atas, maka penulis memberikan saran-saran sebagai berikut: Pertama, orang tua harus lebih memberikan perhatian khusus kepada anak remaja mereka (pendampingan khusus), meluangkan lebih banyak waktu untuk dihabiskan bersama anak 
remaja mereka. Orang tua juga harus memperhatikan setiap keadaan anak remaja mereka, bila mereka pernah menyatakan keinginan untuk bunuh diri, orang tua harus menanggapi hal ini dengan serius. Kedua, Pembina rohani. Pembina rohani secara khusus pembina remaja harus memperhatikan perkembangan remaja mereka. Mencoba untuk memahami dunia remaja saat ini. Memberikan waktu berharga untuk lebih mengenal remaja. Memikirkan program untuk pelayanan remaja yang lebih menyentuh dunia remaja saat ini. Ketiga, Hamba Tuhan hendaklah terlibat dalam pelayanan remaja, misalnya memberikan konseling kepada remaja yang mengalami masalah. Membuat program yang bisa menjangkau lebih banyak remaja. Keempat, sekolah hendaklah mengadakan program pengajaran khusus untuk membangun karakter dan mengenali diri remaja. Selain itu, sekolah juga menyediakan ruangan khusus untuk konseling dan guru yang benar-benar kompeten untuk menangani konseling secara khusus. Kelima, seluruh guru-guru di sekolah Kristen harus membawa murid-mudirnya untuk menerima Kristus sebagai Juruselamat mereka, walaupun guru tersebut tidaklah mengajarkan pelajaran PAK. Dalam pengajaran PAK guru juga harus memperhatikan kebutuhan remaja dari segi fisik, emosi, sosial, religius dan mental.

\section{Ucapan terima kasih}

SMA Kristen diakui Makassar sebagai tempat praktik penulis dan SMA Gamaliel Makassar yang telah mengizinkan penulis untuk mengadakan penelitian dalam penulisan karya ilmiah ini

\section{Alkitab}

\section{KEPUSTAKAAN}

Alkitab. Jakarta: Lembaga Alkitab Indonesia.

Alkitab Penuntun Hidup Berkelimpahan. Malang: Gandum Mas, 2004.

\section{Kamus}

Tim Penyusun Kamus Pusat Pembinaan dan Pengembangan Bahasa. Kamus Besar Bahasa Indonesia. Jakarta: Balai Pustaka, 1995.

\section{Buku-Buku}

Arterburn, Stephen dan Jim Burns. Arahkan Dengan Jitu. Yogyakarta: Andi Affset, 2006.

Gunarsa, Singgih D dan Y. Singgih D. Gunarsa. Psikologi Perkembangan Anak dan Remaja. Jakarta: Gunung Mulia, 1991.

Hadi, Sutrisno. Metodologi Research 3. Yogyakarta: Yayasan Penerbit Fakultas Psikologi Universitas Gadjah Mada, 1987.

Komaruddin. Kamus Riset. Bandung: Aksara, 1984.

Nazir. Metode Penelitian. Jakarta: Ghalia Indonesia, 1998.

Prince, Derek. Rasa Tertolak Bagaimana Mengatasinya. Jakarta: Yayasan Pekabaran Injil 'Imanuel,' 1994.

Usman, Husaini dan Purnomo, Setiady Akbar. Metodologi Penelitian Sosial. Jakarta: Bumi Aksara, 1996.

\section{Wawancara}


Aswin. Wawancara Oleh Penulis. Makassar: 14 April 2009.

Nova. Wawancara Oleh Penulis. Makassar: 1 April 2009.

\section{Internet}

Bunuh Diri, diakses tanggal 30 Maret 2009; tersedia di http://lanalana.wordpress.com/2009/09/ apa-alasan-remaja-bunuh-diri. 